\title{
Adapters for metallurgical equipment
}

\author{
Viktor Artiukh ${ }^{1, *}$, Vladlen Mazur ${ }^{2}$, Sergey Kargin ${ }^{3}$, and Lidya Zakharova ${ }^{4}$ \\ ${ }^{1}$ Peter the Great St.Petersburg Polytechnic University, Polytechnicheskaya, 29, St. Petersburg, \\ 195251, Russia \\ ${ }^{2}$ LLC «Saint-Petersburg Electrotechnical Company», Pushkin, Parkovaya, 56, Saint-Petersburg, \\ 196603, Russia \\ ${ }^{3}$ Pryazovskyi State Technical University, Universytets'ka, 7, Mariupol, 87500, Ukraine \\ ${ }^{4}$ Moscow State University of Civil Engineering, Yaroslavskoye Shosse, 26, Moscow, 129337, Russia
}

\begin{abstract}
New type of shock absorbers named as 'adapter' and prospects of their usage for reduction of contact stress maximum values in assemblies and details of metallurgical equipment are considered. Some industrial examples of adapters usage are shown.
\end{abstract}

\section{Statement of technical problem}

Metallurgical equipment consists of numerous details which are in contact between each other and transfer loads between assemblies. These loads can be technological and nontechnological. Many times non-technological loads are causes of accidental breakdowns or increased wear of expensive parts of metallurgical equipment [1-6].

For example, flat contact surfaces of rolls chocks, lining straps, facing strips and housings of heavily loaded elements of rolling stands can be damaged or broken by dynamic loads during rolling. Damages of lining strap of bottom work roll (WR) chock from drive side (entry and delivery sides of reversing rolling stand of thick sheet rolling mill 3000 of PJSC 'ILYICH iron and steel works' (Mariupol city, Ukraine) are shown on fig. 1 and 2 [7-11].

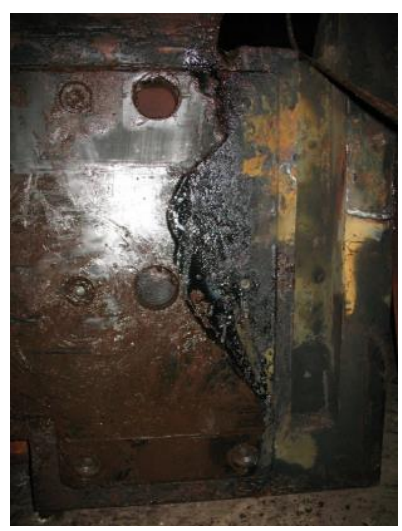

Fig. 1. Damages of lining strap of bottom WR chock from drive side (delivery side).

\footnotetext{
* Corresponding author: artiukh@mail.ru
} 


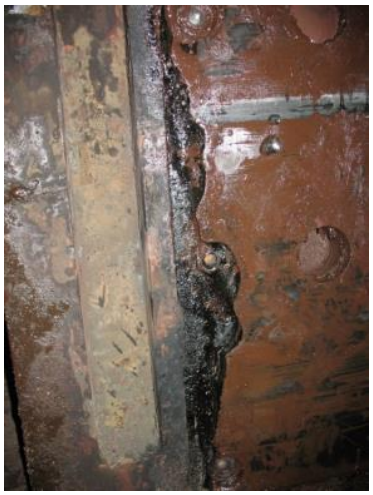

Fig. 2. Damages of lining strap of bottom WR chock from drive side (entry side).

\section{Materials of the research}

Researches of forces acting in rolling stands in the horizontal direction show that their values during metal-in / metal bite by WRs and metal-out can reach their maximum, which for reversing rolling stands of thick sheet rolling mill 3000 of PJSC 'ILYICH iron and steel works' can be around $\mathrm{F}_{\max }=3 \div 4 \mathrm{MN}$ and its value much smaller than vertical rolling force $\mathrm{P}$ [12-14]. $\mathrm{P}_{\max }=60 \div 70 \mathrm{MN}$ in the rolling stands of thick sheet rolling mill 3000 and forces $\mathrm{P}$ act inside rolling stands without plastic deformations and damages of details compared to details undergoing plastic deformations and damages due to dynamic horizontal impact forces F(refer to fig. 3, where pos. 1 is housing, pos. 2 is facing strip, pos. 3 is lining strap, pos. 4 is WR chock, fig. 5 is WR, $\Delta$ is gap between facing strip pos. 2 and lining strap pos. 3 ).

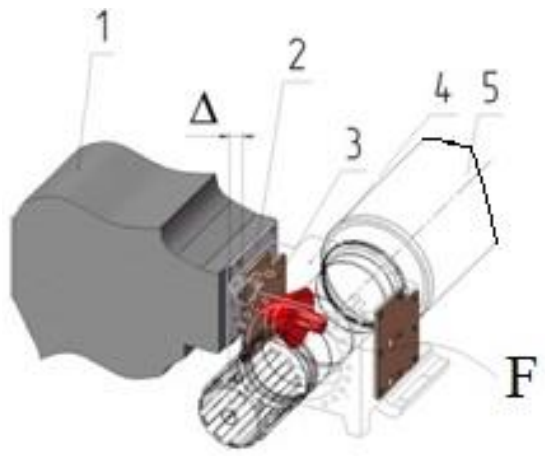

Fig. 3. Scheme of acting of dynamic horizontal force F of WR chock impact against housing.

Attempts to eliminate or revamp damages of contact surfaces of rolls chocks, lining straps, facing strips and housings have been made for many years but it has low success. Main results are in revamp of damages of flat contact surfaces [15] and there are almost no success and technical solutions to prevent damages of flat contact surfaces. Even invention of details made from bimetallic steel (outer surface is from rigid steel e.g. $65 \mathrm{G}$ according to CIS SS 20072-74 and soft inside surface is from soft steel e.g. St3 according to CIS SS 38094) does not stop damages of metallurgical equipment.

Researches of non-technological loads made it possible to reduce their values [16-18]. Big values of non-technological loads during unsteady loading of main drive lines can result in equipment accidental breakdowns $[19,20]$, namely, WRs, slots connections, spindles, couplings, etc. [21, 22]. 
In order to eliminate damages of aforementioned details it needs to reduce stresses on their contact surfaces. Theoretically their contact surfaces designed to work in particular conditions and distributed stresses should be within normal limits. But on practice, there are not full interactions between contact surfaces hence big stresses on their contact surfaces arise. In addition, assemblies made from steels are rigid systems which have been made with high accuracy to improve conditions of interactions. Nevertheless high values of contact stresses arise that is why metallurgical equipment works with breaking-in and test modes before making project productivity.

Taking in consideration above given information two questions arise:

- are designs based on rigid connections the best technical solutions?

- how reduction of contact stresses and increase of rigid connections durability can be achieved?

First of all, technical term 'load' has to be understood with its value and stresses distribution in details due to its loading. Secondly, list of non-technological loads will be increased because of non-uniform contact stresses distribution that results in damages of rolls chocks, lining straps, facing strips, housings, bearings blocks, spindles, couplings, etc.

Nowadays, there is a possibility to liquidate non-technological loads (with non-uniform contact stresses distribution) due to usage of technical solution generally named as 'adapter'. Adapter is a new type of shock absorber (known types are buffer, compensator and damper). Its function is to improve distribution of contact stresses to make their maximum values become smaller.

Principle of adapter work is shown on fig. 4 [23] where FEM is used to make stress calculation. Initial stress distribution with non-uniform contact stresses distribution is shown on fig. 4,b. Better stress distribution is shown on fig. 4,c where:

- $\mathrm{F}=3 \mathrm{MN}$

- $\sigma_{2}{ }^{\max }=104.171 \mathrm{MPa}<<\sigma_{1}{ }^{\max }=219.560 \mathrm{MPa}$.

This result (refer to fig. 4) is achieved due to usage of adapter in a form of elastic lining strap installed on WR chock instead of one made from steel. This lining strap (industrial example of adapter) is made from energy-efficient material e.g. polyurethane [24-28].

Feature of adapters is that their deformation is much bigger than unevenness and defects of contact surfaces that is why non-uniform contact stresses distribution becomes better and maximum contact stresses become smaller.

Example of usage of elastic lining straps installed on finishing group stands of hot strip mill 1700 of PJSC 'ILYICH iron and steel works' is shown below. After modernization of these rolling stands done by Klessim company ultrahigh molecular weight polyethylene (UHMWPE) lining straps were installed instead of steel ones on back-up rolls chocks. Elastic lining straps worked for 24 months (there were no wear and damage of chocks) that is twice bigger compared to steel ones with below given mechanical characteristics:

1. Normal modulus of elasticity $\mathrm{E}=2 \cdot 10^{5} \mathrm{MPa}$.

2. Biggest elastic deformation $\varepsilon_{\mathrm{y}}=0.2 \%$.

3. Biggest elastic stress $\sigma_{\mathrm{y}}=400 \mathrm{MPa}$.

For explanations of above shown 24 months result mechanical characteristics of UHMWPE were investigated: $\mathrm{E}^{1}=300 \mathrm{MPa}, \varepsilon_{\mathrm{y}}{ }^{1}=10 \%, \sigma_{\mathrm{y}}{ }^{1}=30 \mathrm{MPa}$. Their design was similar to steel ones with thickness $\delta=20 \mathrm{~mm}$. It is assumed that stress inside UHMWPE lining straps did not exceed $\sigma \leq 30 \mathrm{MPa}$ because there was no breakdown of them. In addition, $\sigma_{\mathrm{y}}$ is by around 12 times less than stress inside steel lining straps because there were numerous cases of their plastic deformations and damages made to the chocks. Maximum reduction of horizontal forces and contact stress can be around $25 \div 30 \%$ because of adaptation that is adjustment of contact surfaces to each other. Reduction of maximum contact stress (ideal distribution is uniform distribution) results in complete stop of breakdowns of chocks 
and housings (facing strips on housings) which confirms the practice of UHMWPE lining straps usage.

When stress values become bigger than permissible ones elastic lining straps can be used as removable details.
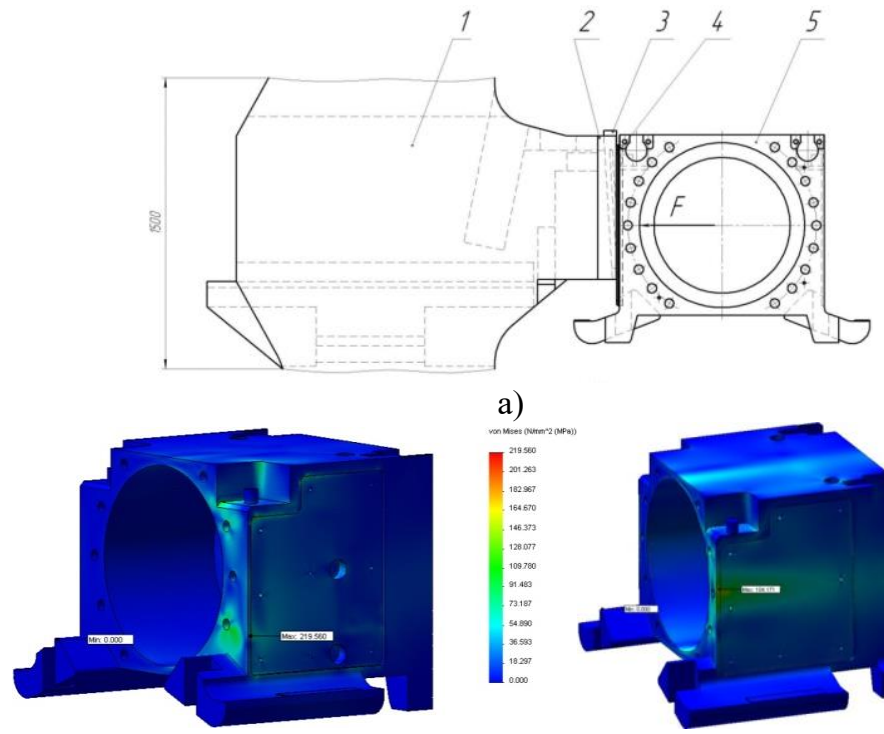

a)

b)

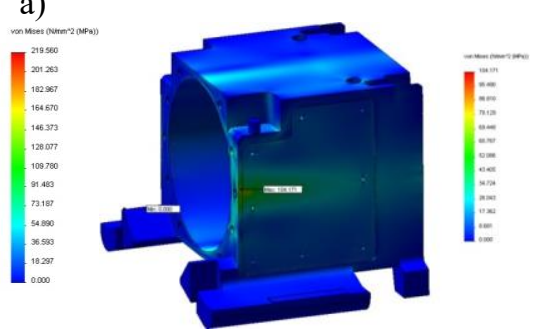

c)

Fig. 4. Stress calculation of bottom WR chock. Where: 1 - housing; 2 - static wedge type facing strip; 3 - movable wedge type facing strip; 4 - lining strap (from steel for fig. 4,b; from polyurethane for fig. 4,c); 5 - bottom WR chock.

There is experience of industrial test of lining straps made from structural polyurethane installed instead of steel ones on WRs chocks of roughing and finishing rolling stands of thick plate rolling mill 3000 of PJSC 'ILYICH iron and steel works'. Industrial test was made for 24 months, 5 sets (40 elastic lining straps) were installed. Main results are:

- almost no wear of contact surfaces of chocks;

- durability of elastic lining straps was around $6 \div 7$ months that is twice less than durability of lining straps from bimetallic steel;

- theoretical economic effect due to usage of elastic lining straps is around $€ 60000$ per year;

- further improvement of these lining straps can increase their durability by $2 \div 3$ times.

In addition, done theoretical calculations show graphs (refer to fig. 5) of relation between dynamic horizontal impact forces $\mathrm{F}$ and gap $\Delta$ between facing strip pos. 2 and lining strap pos. 3 (refer to fig. 3) when lining strap made from different materials [29].

According to fig. 5 it is clear that dynamic horizontal impact force $\mathrm{F}$ is always smaller when lining strap made from polyurethane grade 'Adiprene L-167' compared to F when lining strap made from steel $080 \mathrm{M} 46$ according to B.S. 970 e.g.:

- when $\Delta=1 \mathrm{~mm} F$ decreases by 2.6/2.1 = 1.24 times;

- when $\Delta=2 \mathrm{~mm} F$ decreases by $2.8 / 2.2=1.30$ times;

- when $\Delta=6 \mathrm{~mm} F$ decreases by $3.5 / 2.23=1.57$ times 


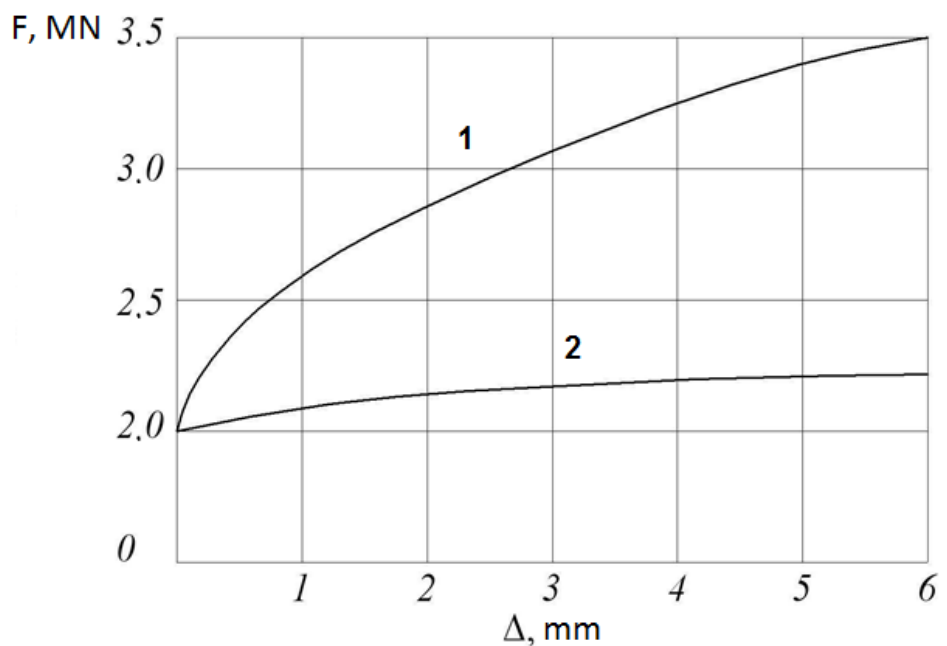

Fig. 5. Graphs of relation between $\mathrm{F}$ and $\Delta$ when lining strap made from: 1 - steel $080 \mathrm{M} 46$ according to B.S. 970; 2 - polyurethane grade 'Adiprene L-167'.

General view of lining straps made from polyurethane 'Adiprene L-167' for roughing and finishing rolling stands of thick plate rolling mill 3000 of PJSC 'ILYICH iron and steel works' is shown on fig. 6 .
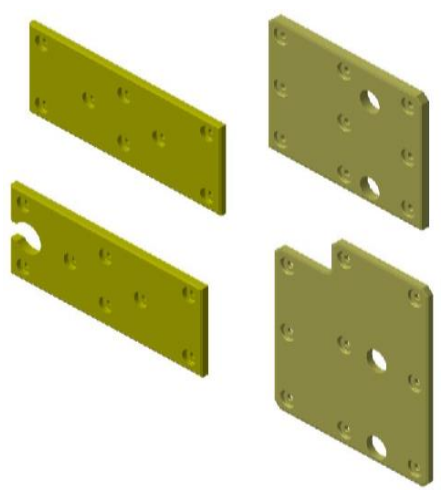

Fig. 6. General view of lining straps made from polyurethane 'Adiprene L-167' for roughing and finishing rolling stands of the thick plate rolling mill 3000.

Another industrial example of adapter is round elastic shock-absorber installed on outer ring of rolling bearing (refer to fig. 7) [30].

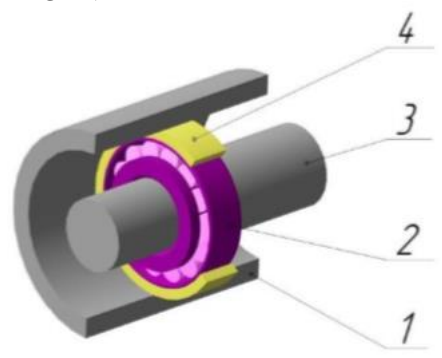

Fig. 7. Scheme of round elastic shock-absorber installation on outer ring of rolling bearing: 1 housing; 2 - rolling bearing; 3 - shaft; 4 - shock-absorber (adapter). 
Problem of $2 \div 3$ months durability of rolling bearings of receiving roller table of hot wide strip mill 1700 and conic roller table of thick sheet rolling mill 3000 both belong to PJSC 'ILYICH iron and steel works' needed to be resolved because cost of mentioned bearings is around $€ 1500 \div 3000$. In addition, there were plastic deformations of housings due to high level of contact stresses.

Main objective of amortization provided by the adapter is to reduce radial nontechnological load acting on bearing by increase of rigid system ability to accumulate potential energy of deformation. Practically, after installation of the adapters (polyurethane rings with $20 \div 40 \mathrm{~mm}$ thickness, refer to fig. 8):

- on the conic roller tables (20 rollers before rolling stand and after, bearing No. 23248) durability of the rolling bearings was increased up to 22 months;

- on the receiving roller table (4 rollers, No. 2097148) durability of the rolling bearings was increased up to 24 months;

- plastic deformations of housings completely stopped.

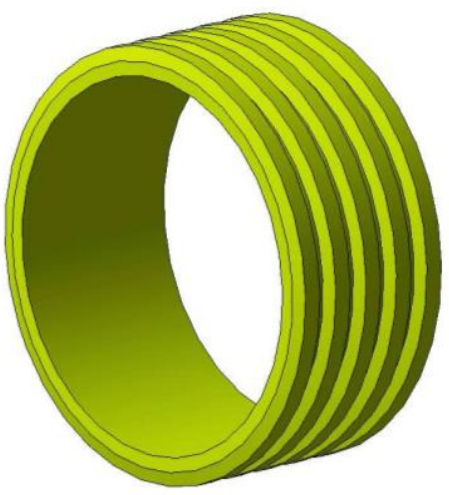

Fig. 8. Polyurethane ring with $20 \div 40 \mathrm{~mm}$ thickness.

On practice, there are numerous damages of contact surfaces of spindles and parts of main drive lines of metallurgical equipment because of big values of driving and dynamic torques. Some damages are shown on fig. 9.
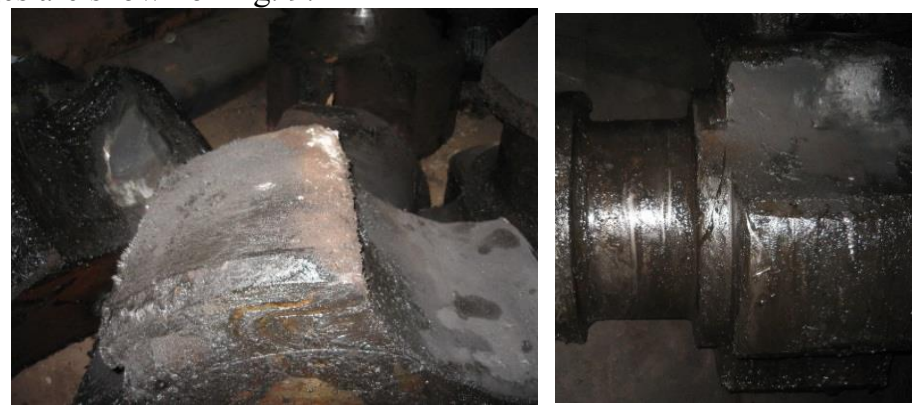

Fig. 9. Plastically deformed ends of spindles of Hot Pipe Rolling Shop with two Pilger stands $6 " \div 12 "$ of PJSC 'ILYICH iron and steel works.

Another industrial example of adapter is elastic plane shock-absorber installed on contact surfaces of spindles and parts of main drive lines of metallurgical equipment (refer to fig. 10 and 11). 


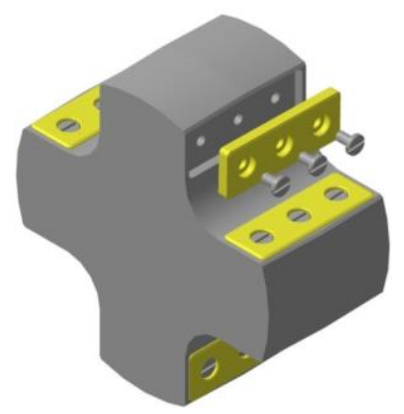

Fig. 10. Polyurethane linings installed on ends of spindles.
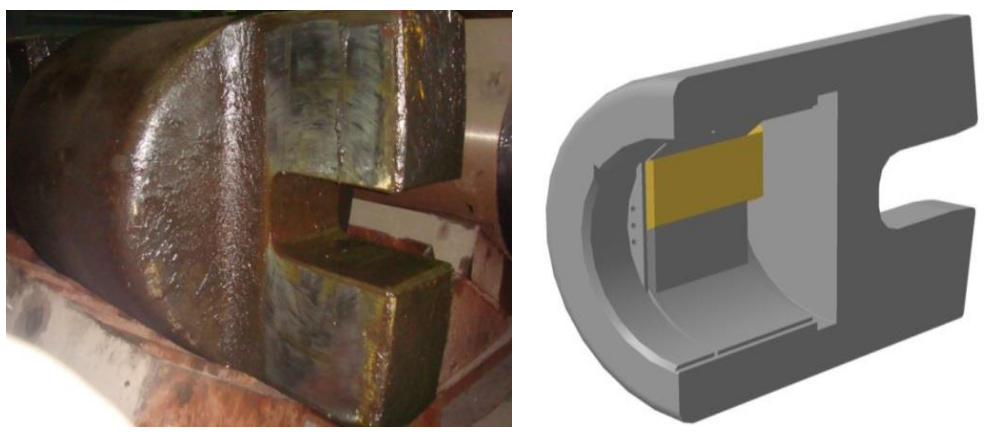

Fig. 11. Polyurethane lining installed on spindle coupling.

Elastic linings installed on ends of spindles prevent plastic deformation of ends of spindles and couplings connected to them. Polyamide or polyurethane linings (refer to fig. 10) are removable parts, their durability is around 6 months.

Elastic lining installed on spindle coupling prevent plastic deformation of ends of spindles, couplings (rolls) connected to them (refer to fig. 11). Polyurethane lining is removable part, its durability is around 6 months.

\section{Conclusions}

1. Use of adapters in assemblies of metallurgical equipment can improve distribution of contact stress and increase durability of contact details.

2. Usually there are possibilities to design technical solutions, make industrial tests and further use of adapters based on initial steel details of metallurgical equipment.

3. Usually bearing units are rigid assemblies. Rolling bearing durability can be increased by adapter installation on its outer ring.

4. High values of driving torques transmitted by spindles, couplings can result in plastic deformations of their contact surfaces. Use of adapters from polyamide or polyurethane can reduce plastic deformations of their contact surfaces.

5. Use of adapters from elastic materials (polyamide, polypropylene, polyethylene or polyurethane) provides reduction of non-technological loads.

\section{Acknowledgments}

The reported study was funded by RFBR according to the research project №16-08-00845a 'Verification and development of models of inelastic deformation at the passive loading'. The authors declare that there is no conflict of interest regarding the publication of this paper. 


\section{References}

1. V.I. Bolshakov, Metallurgical and Mining Industry 3, 89-91 (1998)

2. P.V. Krot, IUTAM Bookseries 27-4, 429-442 (2011)

3. V.V. Verenev, V.I. Bolshakov, A.M. Yunakov, Fundamental and applied problems of ferrous metallurgy: Works 19, 346-358 (2009)

4. V.V. Verenev, V.I. Bolshakov, N.I. Podobedov, Protection of iron and steel machines from failure 3, 35-39 (1998)

5. V. Mazur, V. Artyukh, G. Artyukh, M. Takadzhi, Engineering Designer 37-1, 26-29 (2012)

6. N.S. Gharaibeh, M.I. Matarneh, V.G. Artyukh, Journal of Applied Sciences, Engineering and Technology 8(12), 1461-1464 (2014)

7. V. Kukhar, V. Burko, A. Prysiazhnyi, E. Balalayeva, M. Nahnibeda, East-European Journal of Enterprise Technology 3/7(81), 53-61 (2016) ISSN 1729-3774, DOI: http://dx.doi.org/10.15587/1729-4061.2016.72063

8. V.V. Kukhar, O.V. Vasylevskyi, Metallurgical and Mining Industry 3, 71-78 (2014)

9. V. Sikulskiy, V. Kashcheyeva, Yu. Romanenkov, A. Shapoval, Eastern European Journal of Enterprise Technologies 4-1(88), 43-49 (2017) DOI: 10.15587/17294061.2017.108190

10. V. Dragobetskii, A. Shapoval, E. Naumova, IEEE International Conference on Modern Electrical and Energy Systems (MEES), 400-403 (2017) DOI: 10.1109/MEES.2017.8248944

11. E. Sorochan, V. Artiukh, B. Melnikov, T. Raimberdiyev, MATEC Web of Conferences, 73, 04009 (2016) DOI: http://dx.doi.org/10.1051/matecconf/20167304009

12. V. Mazur, V. Artiukh, M.I. Matarneh, Procedia Engineering 165, 1722-1730 (2016) DOI: 10.1016/j.proeng.2016.11.915

13. V. Artiukh, V. Mazur, A. Adamtsevich, MATEC Web of Conferences 106, 04001 (2017) DOI: https://doi.org/10.1051/matecconf/201710604001

14. V. Artiukh, V. Mazur, L. Shilova, MATEC Web of Conferences 106, 03002 (2017) DOI: https://doi.org/10.1051/matecconf/201710603002

15. I.V. Alexandrov, Metal and casting of Ukraine 3- 4, 51-52 (2004)

16. Y. Konno, S. Shibuya, S. Tanaka, Kawassaki Giho 33, 37 - 42 (2001)

17. Heavy-plate mills, Hot Rolling Mills Division (SMS SIEMAG, Hilchenbach, 2012)

18. A.A. Ishenko, Steel 5, 56-58 (2009)

19. A.A. Ishenko, Metallurgical processes and equipment 3, 23-25 (2008)

20. V. Artiukh, V. Mazur, A. Butyrin, EMMFT 2017. Advances in Intelligent Systems and Computing, Springer 692, 212-219 (2018) DOI: https://doi.org/10.1007/978-3-31970987-1_23

21. V. Artiukh, V. Mazur, E. Nidziy, International Scientific Conference Energy Management of Municipal Transportation Facilities and Transport EMMFT 2017, Advances in Intelligent Systems and Computing, Springer 692, 1065-1073 (2018) DOI: https://doi.org/10.1007/978-3-319-70987-1_115

22. V. Artiukh, V. Mazur, E. Pokrovskaya, MATEC Web of Conferences 86, 01030 (2016) DOI: http://dx.doi.org/10.1051/matecconf/20168601030

23. V. Artiukh, T. Raimberdiyev, V. Mazur, MATEC Web of Conferences 53, 01039 (2016) DOI: http://dx.doi.org/10.1051/matecconf/20165301039 
24. L.I. Ogorodov, Mechanics of Composite Materials 30-6, 771-780 (1994)

25. I.I. Loginova, D.A. Artamonova, O.N. Stolyarov, B.E. Melnikov, Magazine of Civil Engineering 4, 11-18 (2015) DOI: 10.5862/MCE.56.2

26. S.N. Yakovlev, V.L. Mazurin, Magazine of Civil Engineering 6, 53-60 (2017) DOI: 10.18720/MCE.74.5.

27. F.M.F. Al-Quran, M.E. Matarneh, V.G. Artukh, Research Journal of Applied Sciences, Engineering and Technology 4(11), 1585-1589 (2012)

28. V.G. Artiukh, S.Yu. Karlushin, E.N. Sorochan, Procedia Engineering 117, 938-944 (2015) DOI: 10.1016/j.proeng.2015.08.180

29. A.A. Ishenko, Issledovanie dinamicheskih nagruzok na stanini kleti stana $3000 v$ processe prokatki i razrabotka predlozeniy po optimizacii ego raboti, Scientific work report (PSTU, Mariupol, 2006)

30. V. Artiukh, M. Belyaev, I. Ignatovich, N. Miloradova, IOP Conf. Series: Earth and Environmental Science 90, 012228 (2017) DOI:10.1088/1755-1315/90/1/012228 